\title{
Collecting and registering sexual health information in the context of HIV risk in the electronic medical record of general practitioners: a qualitative exploration of the preference of general practitioners in urban communities in Flanders (Belgium)
}

\author{
Jolien Vos ${ }^{1,2}$, Peter Pype $^{2}$, Jessika Deblonde ${ }^{3}$, Sandra Van den Eynde ${ }^{4}$, Karolien Aelbrecht ${ }^{2}$, \\ Myriam Deveugele $^{2}$ and Dirk Avonts $^{2}$ \\ ${ }^{1}$ School of Health and Social Care, College of Social Science, Community and Health Research Unit, University of \\ Lincoln, Lincoln, UK \\ ${ }^{2}$ Department of Family Medicine and Primary Health Care, Ghent University, Belgium \\ ${ }^{3}$ Belgian Scientific Institute of Public Health, Brussels, Belgium \\ ${ }^{4}$ Sensoa, Antwerp, Belgium
}

\begin{abstract}
Background and aim: Current health-care delivery requires increasingly proactive and inter-professional work. Therefore, collecting patient information and knowledge management is of paramount importance. General practitioners (GPs) are well placed to lead these evolving models of care delivery. However, it is unclear how they are handling these changes. To gain an insight into this matter, the HIV epidemic was chosen as a test case. Methods: Data were collected and analysed from 13 semi-structured interviews with GPs, working in urban communities in Flanders. Findings: GPs use various types of patient information to estimate patients' risk of HIV. The way in which sexual health information is collected and registered, depends on the type of information under discussion. General patient information and medical history data are often automatically collected and registered. Proactively collecting sexual health information is uncommon. Moreover, the registration of the latter is not obvious, mostly owing to insufficient space in the electronic medical record (EMR). Conclusions: GPs seem willing to systematically collect and register sexual health information, in particular about HIV-risk factors. They expressed a need for guidance together with practical adjustments of the EMR to adequately capture and share this information.
\end{abstract}

Key words: communication in health care; proactive sexual health; sensitive information; sexual risk behaviour

First published online 21 October 2015

\section{Introduction}

Since 1980, general practice has evolved progressively from dealing with acute episodic problems to offering continuous personalised care for

\footnotetext{
Correspondence to: Jolien Vos, School of Health and Social Care, College of Social Science, Community and Health Research Unit, University of Lincoln, Brayford Pool, One Campus Way, Lincoln, LN6 7TS, UK. Email: jvos@lincoln.ac.uk
}

chronic conditions. Besides the traditional solo practice, GPs are increasingly part of interdisciplinary group practices. Two significant shifts in the professional practice of GPs that require further attention.

First, current health-care delivery requires a shift from reactive clinical work (responding as and when the problem is presented by the patient) at the individual level (curing the diseased) to more proactive clinical and organisational work 
(preventing diseases and controlling implications) at the population level (KCE, 2012). This entails the implementation of opportunistic screening, case finding and prevention programmes. At the level of clinical practice, this means informing and educating every patient on health status and risk behaviour. This includes a proactive approach where the GP takes the initiative to introduce preventive activities to the patient, based on data (eg, context information or risk factors) collected during clinical encounters. Therefore, GPs should have a comprehensive view of the health context of their patients as they potentially hold a pivotal position in monitoring the overall health of their patients, including their sexual health [World Health Organisation (WHO), 2012].

Second, solo practices in primary care are replaced by interdisciplinary group practices. Inter-professional collaborative practice is promoted by the WHO Framework for Action on Inter-professional Education \& Collaborative Practice as a way of strengthening health systems and improving health outcomes (WHO, 2012). Essential for quality and continuity of care, in such a 'community of practice' (Parboosing, 2002), is knowledge management: a process of developing, sharing and making existing knowledge about a particular patient available among health-care providers involved (Orzano et al., 2009). Clear and accurate patient information collected in the electronic medical record (EMR) is, therefore, a prerequisite for high-quality patient care (Agarwal and Crooks, 2008). It is no longer sufficient to 'remember' context and sensitive information as practitioners; it needs to be reported in the EMR. In this way, colleagues can access the information in order to ensure the continuity of high-quality, holistic patient care and proactive approaches. However, the sexual health information is not available for other health-care workers to treat the patient in a proactive way. Therefore, the lack of a comprehensive registration of sexual health information in the EMR threatens high-quality patient care.

The HIV-epidemic transition from acute and deadly to a chronic disease exemplifies the rapid health-care changes, which has implications for health-care professionals in primary care (Plsek and Greenhalgh, 2001). Several public health campaigns have improved general awareness of HIV and risky sexual behaviour (European
Centre for Disease Prevention and Control, 2012; Sensoa, 2012). Unfortunately, HIV transmission remains high in men who have sex with men (MSM). Like other European countries, Belgium experienced a steady increase of HIV diagnoses in the past decade: 952 newly infected patients in 2000; 1069 in 2005 and 1196 in 2010 (Sasse et al., 2012; Sasse et al., 2013). In 2013, the Belgian Scientific Institute of Public Health reported 1115 newly infected HIV patients: $50 \%$ infected via homosexual contact and $45 \%$ via heterosexual contact. Heterosexual transmission is especially seen in the population originating from Sub-Saharan Africa. Looking at heterosexual transmission, the detected new HIV diagnoses decreased by $19 \%$ between 2012 and 2013. In the same period, infections through homosexual contact increased by 5\% (Sasse et al., 2014). The increasing trend of HIV diagnoses among MSM is prominent in urban areas in Flanders: the majority of HIV-infected MSM live in the cities of Brussels, Antwerp, Leuven and Ghent. In addition, $40 \%$ of the newly detected HIV diagnoses in MSM in 2013 are late diagnoses (CD $4<350 / \mathrm{mm}^{3}$ at the moment of the HIV diagnosis), compared with $30 \%$ late diagnoses among MSM in 2012 (Sasse et al., 2014).

The increasing incidence of HIV diagnoses in MSM, despite public awareness and targeted campaigns to MSM, demands a change in the preventive strategy. According to the literature, GPs could play an important role in preventive counselling and early detection of an HIV infection (Wimberly et al., 2006; Khan et al., 2007; Meystre-Agustoni et al., 2011). Nevertheless, a coherent overview of the role of GPs in a new strategy to decrease HIV transmission in MSM is often missing (Khan et al., 2007; Verhoeven et al., 2007).

Appropriate data collection, discussion of sexual health issues and registration of the yielded information in the EMR in primary care could support a proactive approach in the management of HIV/AIDS. This is particularly needed in MSM with risky sexual behaviour. Because of their position in health care, GPs should lead this new strategy to reduce the number of new HIV infections among MSM and to detect new HIV infections at an early stage of the disease.

Yet, it is unclear how GPs collect, discuss and register sexual health information in the EMR, or 
how they share it with colleagues. Investigating the ways in which GPs currently use the EMR to record sexual health information will offer insights to improve the collection of sexual health information and identify barriers and facilitators to sharing this information with other health-care providers.

We explored the following research questions:

- What are important HIV-risk factors according to GPs?

- How, where and when do GPs collect/discuss information about HIV risk?

- How, where and when do GPs register information about sexuality and sexual health and can this be improved?

\section{Methods}

\section{Study setting and participants}

This explorative study used face-to-face interviews to address the research questions. We selected a purposive sample of GPs currently involved in one or more aspects of HIV care for MSM; a follow-up of HIV patients, preventive counselling, voluntary testing and counselling, screening for sexually transmitted infections (STIs), or partner notification. We initially sought a sample of 10-15 participants based on the following inclusion criteria: they had to be GPs practising in an urban Flemish community in view of the concentration of HIV-infected MSM living in urban areas and having many years of clinical experience in treating or/and screening of HIV patients. Purposive sampling was chosen because of the explorative focus of the study, the limited existing knowledge regarding the topic and the need to retrieve detailed information. The researchers sought participants of different genders and from different geographic areas in order to capture a diversity of perspectives and identify any differences.

Permission was obtained for this qualitative explorative study from the ethical commission (EC/2011/512) of Ghent University (Belgium).

\section{Data collection}

Semi-structured interviews were conducted by the first author using an interview protocol (Appendix 1) based on the literature, revised by experts in clinical follow-up of HIV patients and health-care workers involved in research on sexual behaviour of MSM. Sexually risky behaviours in this study encompass intimate contacts that can transmit sexually transmitted microorganisms: oral sex with and without ejaculation in the mouth, unprotected vaginal or anal penetration, cunnilingulus and anilingulus. In terms of HIV transmission, unprotected vaginal or anal intercourse with casual partners is seen as risky behaviour.

The information needed for this study was collected with open-ended questions to provide the participant with every opportunity to give full answers and minimise the potential for bias. After every third interview, the interview protocol was reviewed and adapted if needed. The interviews lasted approximately one hour and were tape recorded with the written consent of the GPs involved.

\section{Data analysis}

The interviews were transcribed verbatim, anonymised and open coded manually line by line by one researcher. The ongoing coding process started close to the text and moved up to a more abstract level. During the second coding phase, two researchers independently coded the transcriptions, producing a number of emergent themes. All significant fragments were analysed thematically using a flexible model for analysis (Appendix 2). Based on the axial and open codes, different categories were created to capture all significant and meaningful fragments and to interpret the data.

\section{Results}

Socio-demographic characteristics of the sample

In total, 13 GPs, aged 29-65 years, were interviewed (seven males and six females). The GPs were working in Antwerp, Brussels, Ghent or Leuven, in local health centres (seven) or in group practices (four) and two were practicing solo (Table 1).

\section{Important HIV-risk factors according to GPs}

All participants stated that the risk of HIV in Flanders was closely linked with engaging in sexually risky behaviour. However, information on 
Table 1 Sample characteristics

\begin{tabular}{lllll}
\hline Participants & \multicolumn{2}{l}{ Characteristics } & & \\
\cline { 2 - 5 } & Sex & Age & City of practice & Practice composition \\
\hline GP1 & Female & 29 & Ghent & Local health centre \\
GP2 & Female & 31 & Ghent & Local health centre \\
GP3 & Female & 44 & Ghent & Local health centre \\
GP4 & Male & 31 & Antwerp & Local health centre \\
GP5 & Male & 32 & Antwerp & Local health centre \\
GP6 & Female & 44 & Leuven & Group practice \\
GP7 & Male & 56 & Brussels & Group practice \\
GP8 & Female & 42 & Brussels & Group practice \\
GP9 & Male & 61 & Ghent & Local health centre \\
GP10 & Male & 31 & Brussels & Local health centre \\
GP11 & Female & 35 & Brussels & Solo practice \\
GP12 & Male & 65 & Leuven & Solo practice \\
GP13 & Male & 61 & Leuven & \\
\hline
\end{tabular}

sexual behaviour was not collected directly. Instead, they assessed information that gave indirect information regarding HIV-risk behaviour.

GPs in this study used several types of patient information to evaluate the risk factors for HIV, in particular, gender; stage of life; country of origin; previous STIs; and sexual orientation.

According to the interviewees, certain stages of life involved more sexually risky behaviour and consequently, the patients' age was perceived as an important item.

'The youth, yes, especially their debauched behaviour... They don't seem to know that they've a responsibility to take in their sexual behaviour...'.

(GP12)

'Also, the older man is at risk ... because of ... the changes in his sexual life, the closure of the woman on hormonal base, so often the libido disappears in woman and the man is left unfulfilled ... not the young but the old fool ... they search elsewhere for sexual contacts and it happens that they do expose themselves to risky contacts'.

(GP12)

Second, GPs stated that the patients' country of origin was an important factor because of the prevalence and incidence of HIV among some

\footnotetext{
${ }^{1}$ The quotes are free translated from Dutch.

migrant populations in Flanders, in particular SubSaharan Africans (SAM).

'For our black patients, everyone knows, you can simply see it ... so of course, it's a black patient, we have to ask for HIV and we know that and you can see that. We are trained to do so'.

(GP1)

'At the moment, we have a project regarding Sub-Saharan Africans [SAM], the SAMproject, so because of that, I pay more attention to it. The idea is to speak sooner about an $H I V$-test with those patients, to screen them. Because of the higher prevalence, so yes, I'm triggered to ask for it among those patients'.

(GP5)

Third, patients' medical history of previous STIs and/or STI screening alerted all participants, as it identified sexual risk behaviour in the past.

'Sexual risk behaviour is obviously the most important risk factor, so of course patients who had a STI in the past are patients at risk ...'

(GP11)

'There are some things that are present in the medical record; I mean we weren't born yesterday. A HIV-test, says something, if there are some tests in the past, well they weren't taken for nothing .... 
Finally, the sexual orientation was perceived as important information regarding the risk of HIV for the patient.

'I think an important group at risk in our practice, are the homosexuals. Of course you cannot put them all in the same box, but still. It's known that among homosexuals the risk is higher'.

(GP8)

\section{Collecting information about HIV-risk factors and discussing sexual health}

There were two different ways in which HIVrisk information was collected. First, 'general information' (eg, age, previous STI or STI screening) was gathered in a more systematic way during the history taking or derived from the patient's medical record in the past.

\section{'All STIs are noted in the medical record. So if there was one in the past, you will know it and you also know that, in that case, the risk of HIV is higher'.}

Second, there was the more 'sensitive sexual information' (eg, sexual orientation) that was only discussed if an opportunity arose, either because the patient presented a complaint or because the patient initiated the discussion.

'A sexual history taking? I do this rather adhoc ... I think we do that too little, only if there are certain occasions'.

(GP10)

'Sometimes, it's something that is mentioned as a casual remark or the patient is asking you casually for a blood sample'.

Without such opportunities, GPs faced some obstacles to starting a conversation about the patient's sexual orientation and mostly relied on their assumptions.

'After so many years, there are few who escape our attention ... Of course, there are a lot of bisexuals where we do not know it from'.

(GP7)
'I'm afraid that I'll scare patients by asking for sexual risk behaviour right away'.

Collecting or systematically assessing this information directly often proved to be difficult because of the sensitivity and ambiguity of sexually risky behaviour.

'Smoking is easy, you smoke or you don't, it's different with sexual stuff, there isn't something as "normal behaviour" and the rest is aberrant ...'.

(GP10)

'Smoking is something more common and less emotionally-charged than sexuality'.

All GPs interviewed felt that a more proactive approach for gathering sexual health information was desirable, but some recognised that this was not easily achieved in practice. Most participants believed that asking for some potential HIV-risk factors (eg, sexual orientation, marital status) during history taking, could promote a proactive approach and encourage patients to discuss sensitive issues more openly.

'If you are asking during history taking, people are in the rhythm of 'yes', 'no' and if there comes a question about sexuality, it will be less shocking'.

GPs stated that patients also have a role to play and only using campaign posters to raise awareness among patients is no longer sufficient to activate patients' role in this matter.

'To take their own responsibility and tell them that if something happens, they have to take action, they have to get a test'.

(GP11)

'A poster in the waiting room ... I've done it, but it doesn't bring in. You will have to start the conversation, and I think some standard questions are very suitable for this, it's small, but you break down some barriers!'.

(GP13)

The integration of standard questions would provide GPs with a better view of their patients'

Primary Health Care Research \& Development 2016; 17: 333-350 
sexual health. Depending on the answers to these questions, a more detailed assessment of the sexual history could take place.

To adopt this more proactive approach during history taking and later on with an in-depth sexual history, GPs need guidelines regarding the assessment of sexual risk behaviour. However, according to the interviewees, there is currently no such guideline available, which makes it more difficult to handle. Analogously to the SAM project, which promotes 'standard' HIV testing among all SAM Migrants in Flanders, most GPs thought it would be desirable to have a similar protocol for HIV testing among other patients.

'We don't have a protocol to ask for sexualrelated questions, neither to register the information. I think we need to change that, like with the SAM project but for homosexuals and other patients at risk'.

(GP1)

\section{Registering HIV-risk factors in the medical record}

The 'general information' concerning HIV-risk factors could often be found in a specific place in the EMR. The date of birth was present in the administrative part, previous STI and/or STI screenings were components of the medical history, both of which were part of the medical record. The way patients' countries of origins were noted in the EMR varied across practices. Some GPs noted the country of origin; others reported that this derived from the name and skin colour of the patient and they did not feel the need to register it explicitly.

'For black patients, I also list the county of origin as administrative information'.

'You know, of course the origin is an important risk factor for HIV, but you can see this in the name. This is different for the sexual orientation'.

(GP1)

All these elements had a specific assigned place in the EMR. An indication for patients' sexual orientation (sensitive sexual information), which most interviewees identified as a main risk factor, was however, not presented in the EMR.
'Moreover, there is a place in the EMR for it [smoking]! But in the end, they serve the same ... they are both important in estimating a patient's health risk'.

All GPs proposed storing this information in a striking and visible place. A majority thought it would be beneficial to systematically register the sexual orientation of the patient, especially in group practices. Nevertheless, a small minority of GPs in this study felt that registering the sexual orientation was unnecessary; it was something they 'knew and remembered'.

'I think it's very important to know the sexual orientation, but I remember it, I don't write it down, I remember my homosexual patients, my prostitutes'.

(GP12)

'I just remember it ... of course for my colleagues, that isn't ideal, but I remember it and I'm careful in what I register'.

'I think we should all register it more systematically, with the possibility of all orientations, because otherwise your colleagues cannot find out if you already asked for it or not'.

Three options to register this type of sexual (health) information were mentioned. First, GPs could capture this information in the consultation summary in the medical record. A second possibility was to register it as 'personal notes'. The third option reported by some interviewees, was to give the code 'at risk of STI' (International Classification of Primary Care code: 'Fear of HIV') (Wonca International Classification Committee, 2012). According to the participants, none of these possibilities sufficiently captured the (sensitive) sexual health information. This was either owing to the lack of space to specify or because it was not visible enough for colleagues.

'No, we don't register homosexuality, well ... maybe if the patient himself gives us this information; it may end up in the summary of the consult. But I don't think anyone will search for it there, it isn't visible, you understand?' 
'There is no place for it in the record, you cannot fill in such things, if the programme must allow that, I would fully do it'.

'I can hardly put one extra line of free text, that's not enough to explain sexual risk behaviour!'.

In addition, the lack of guidelines for registering and discussing made it hard for the participating GPs. Some GPs in inter-professional settings also reported the need for guidance on information sharing. It wasn't always clear who had access to the EMR and it was stated that a privacy policy was something they needed to define more specifically for this.

'Mmh who has access? Good question, doctors and nurses, unreservedly and people at the reception, but they aren't supposed to use it to get information, but they can see it. Recently, the question came because we are growing as a local health centre, if social assistants, psychologists, dieticians, etc., ... get access or not. But that's a discussion. A lot of the people here were against that idea, we decided to give the information they need in a letter'.

(GP10)

'In theory, everyone who's working here in the local health centre has access. I know that elsewhere this isn't always the policy and that it is reserved, but here in theory everyone can see the EMR. In practice ... only the doctors use it'.

(GP3)

\section{Discussion}

Participants do not tend to routinely collect information on sexual behaviour from all patients. Instead, they narrow information on HIV risk to certain patients' characteristics. The results of our qualitative study show three main types of patients' information through which GPs evaluate their patients' risk for HIV: (1) socio-demographic data such as age, sex and country of origin; (2) elements in the medical history, especially previous STI's and/or episodes of STI screening; and (3) sexual health information, which is often interpreted in the direction of sexual orientation rather than current sexual practice. Depending on the type of patient information, the discussion with the patient, collection of the information and registration in the EMR differ.

\section{Collection of information}

Collecting demographic data and medical history are routine procedures in general practice. The information either derives from the previous medical record of the patient, is queried by the GP or by the paramedic staff at the reception. Yet, in some practices, there is limited verifying of information. This is, for instance, the case with information about patients' country of origin. Based on the characteristics of the surname and the skin colour of the patient, GPs indirectly assume patients' country of origin rather than directly inquiring about it.

All participants are aware that the collection of sexual health information is incomplete and often ad hoc. Although GPs find this information important, it is rarely available in the medical records of the patient, nor part of general history taking. The incomplete collection of sexual health information, in particular HIV-risk factors, is in line with other studies (Khan et al., 2007; Verhoeven et al., 2007). Sexual behaviour is hardly discussed without the clinical presentation of a genital complaint (Hinchliff et al., 2004; Tsimtsiou et al., 2006; Wimberly et al., 2006; Khan et al., 2008; Brandenburg and Bitzer, 2009). Conversely, research from patients' perspectives reveals that patients seem to wait for the initiative of their GP to start discussing these issues (Kang, 2007; Parish and Clayton, 2007; Ralston et al., 2007; Verhoeven et al., 2007; Byrne et al., 2010; Meystre-Agustoni et al., 2011).

GPs in the study often based their assumptions regarding sexual health issues on patients' country of origin and their sexual identity rather than on discussing their sexual practices directly. Limiting sexual health information to characteristics, such as sexual orientation and age, further illustrates the reluctance of GPs to openly discuss sexual issues with the patient. Moreover, GPs do not systematically question the sexual orientation of their patients, but instead they rely on their assumptions or interpretation of observations. Asking for sexual orientation, is asking for 
identity, like gender. Not only may people feel embarrassed to reveal their sexual orientation or fear stigma and discrimination, they may also not identify themselves, for example, as being homosexual. All of which can create a barrier in the patient-doctor interaction. Collecting sexual health information, however, requires a broader focus on current sexual behaviour instead of identity. Focussing on sexual behaviour might take away some of the barriers, for example, fear of stigma, for both patients and GPs. The 2013 UK national guideline for consultations requiring sexual history taking recommends 'the use of sexually explicit language within the sexual history consultations and use language that is clear, understandable and with which both clinician and patient are comfortable' (Brook et al., 2014). As such, the integration of information on sexual behaviour, like anal penetration or vaginal intercourse, in the assessment of HIV risk would facilitate the patient-doctor communication and could decrease the ambiguity (Buysse et al., 2013).

Furthermore, HIV-risk factors may change over time and therefore, information on current sexual practices is an essential element of sexual health information. Unprotected sexual behaviour among MSM in a partner relationship, for instance, does not necessarily create an immediate risk for HIV transmission, if both partners are HIV negative and have no unprotected sexual contact outside of the relationship. A break in a monogamous relationship on the other hand can, for instance, bring along high-risk behaviour with casual partners of whom the serostatus is unknown (Prestage et al., 2006; Mitchell et al., 2012). Collecting adequate sexual health information, but also a regular check of the registered information is a condition to keep the information up to date and useful for all health-care workers involved.

In order to move towards such a proactive approach, GPs report the need for support in 'when' and 'how' to get this sexual health information; a 'tool' to help them to obtain sexual health information systematically. Previous research shows that computer-assisted sexual history taking in a sexual health clinic setting increases the response rate to sensitive sexual information with $40 \%$ compared with paper and pen, and produced more complete data (Richens et al., 2010). In particular, the question concerning sexual behaviour with persons of the same sex had a three times higher response rate (Spark et al., 2015). Adding some specific questions to the general history taking, entered by the patient on an electronic or paper form might be an option: computerassisted self-interview (CASI) or computer-assisted personal interview (CAPI). In case of CASI, the patient enters the information in a private setting, whereas with the CAPI, the information is entered by the clinician during a face-to-face interview (Richens et al., 2010). This patient entered information is evaluated by the GP, who decides whether to probe sexual history further or not.

\section{Registration of information}

Demographic data and medical history are almost automatically incorporated in the EMR. Yet, the structure of the EMR in Flanders does not help to overcome barriers in the appropriate registration of sexual health information. Participants demand an easily accessible place in the EMR to register and consult this information. According to the GPs in our study, the EMR programmes comprise a range of ways to register health information, such as coding the diseases, written consultation summaries and checkboxes for specific patient characteristics.

Usually, contextual health information ends up in the consultation summary, a place in the EMR that is often overlooked in time. Contextual information can also be entered as free text in the 'personal notes' section of the EMR. In accordance to the Belgian law on patient rights, the information written as 'personal notes' is exclusively reserved for the physician entering the information and is not accessible to other physicians or health-care workers involved in the patients' care. These 'personal notes' are only accessible to the patient through another physician, acting as intermediary (FPS Public Health, Food Chain Safety and Environment, 2007). When patient information is registered in the EMR with the intention to inform other clinicians involved in the patients' treatment, the information can therefore not be characterised as 'personal notes'. Instead, contextual information has to be registered in a section of the EMR that is accessible to other health-care workers involved, for example, in a section 'risk factors'.

An alert on the main screen of the EMR, indicating that some information is stored in a 
specific compartment of the EMR, could lead the health-care workers involved to the stored information.

Currently, there are no accurate and detailed classification systems to store sensitive contextual information in a coded form in the GPs' EMR. The International Classification of Primary Care, second edition only provides the following codes; P09: sexual preference concern, P29: psychological symptoms/complaints, Y08: sexual function symptoms/complaints and Y24: fear of sexual dysfunction (Wonca International Classification Committee, 2012). These codes offer non-specific information and, according to our participants, do not cover the yielded information after a discussion about specific sexual risks with a patient. Therefore, it is not clear where and how to store this type of information in the EMR, with a view to share this with relevant other health-care workers.

A proactive approach in primary care creates a role for the patient as well as for the GP. By informing and educating patients at risk for HIV, they can actively participate in their own health plan. An alternative way for entering contextual information can be found in the electronic Patient health record (ePHR). The patient manages, together with his care team, the information collected in this record. The patient himself can enter the contextual information in the ePHR, store health information, gain insight into health behaviours through tailored questionnaires and applications imbedded and can give access to a fixed number of physicians to read and use this information (Padman et al., 2010; Witry et al., 2010; Archer et al., 2011). Ideally these ePHRs create the opportunity to share information with certain health professionals (with the explicit consent of the patient), to create links with the EMR or to start discussions about sexual health. This procedure is consistent with the privacy legislation, but limits the accessibility of the information to the rest of the care team involved in the care and treatment of the patient.

These structural and technical problems with electronic records are most apparent in relation to complex care and/or sensitive issues. However, it is in these situations that sharing contextual information and using proactive approaches are of particular importance for the high quality and continuity of care, like preventing a HIV infection or detecting it in an early stage of the disease. The shift to group practices and, in particular, inter-professional practices, raises some questions regarding the access to EMRs. Most practices do not have clear arrangements on who has access to the EMR and whether this differs according to discipline. One must find a way of simultaneously safeguarding the patients' best interests while protecting their privacy.

\section{Strengths and limitations}

The findings of this study must be interpreted with caution. It focuses on a small and specific sample of participants who are familiar with HIV in their clinical practice. This has implications for wider extrapolation. Most GPs in this study are well known as physicians caring for MSM or also participated in the SAM project of the Institute of Tropical Medicine. The latter was a project designed to raise awareness for HIV testing among the Sub-Saharan population in Flanders. This can explain the awareness regarding HIV in this population in their practice. Nevertheless, this study reveals a variety of barriers and opportunities to collect sexual health information, the incorporation into the EMR, and the problems with sharing sensitive information among healthcare workers.

With these limitations in mind, the results show a way to optimise practice in handling sexual health information. There is a need for standards concerning the type of sexual health information, including sexual behaviour, and how to collect it; the frequency of discussing sexual health behaviour; the way in which information has to be registered in the EMR; as well as how to provide access to sensitive information in interprofessional group practices.

\section{Conclusion}

Obtaining and registering information regarding HIV-risk factors is based on demographic data, medical history and collected sexual health information. Demographic information and medical history is routinely recorded in the EMR. Yet, obtaining sexual health information is a sensitive issue in general practice: systematic questioning is lacking, and there is not an appropriate place in 
the EMR for storage and sharing of this information. However, interest is growing for a proactive approach to register the HIV risk. This requires a guideline to collect data to evaluate patients' risk systematically, as well as to share these data with colleagues. An improvement of the patientdoctor communication concerning sexual health issues is needed, concomitant with an adaptation of the EMR to store and share this confidential information.

\section{Acknowledgements}

The authors acknowledge the CaHRU Study Review Group from the University of Lincoln for their input in the development of this paper.

\section{Financial Support}

This research received no specific grant from any funding agency, commercial or not-for-profit sectors.

\section{Conflicts of Interest}

The authors declare that there are no conflicts of interest.

\section{References}

Agarwal, G. and Crooks, V.A. 2008: The nature of informational continuity of care in general practice. British Journal of General Practice 58, 17-24.

Archer, N., Fevrier-Thomas, U., Lokker, C., McKibbon, K.A. and Strauss, S.E. 2011: Personal health records: a scoping review. Journal of the American Medical Informatics Association 18, 515-22.

Brandenburg, U. and Bitzer, J. 2009: The challenge of talking about sex: the importance of patient-physician interaction. Maturitas 63, 124-27.

Brook, G., Bacon, L., Evans, C., McClean, H., Roberts, C., Tipple, C., et al. 2014: 2013 UK national guideline for consultations requiring sexual history taking. International Journal of STD \& AIDS 25, 391-404.

Buysse, A., Caen, M., Dewaele, A., Enzlin, P., Lievens, J., T'Sjoen, G., Van Houtte, M. and Vermeersch, H. (editors) 2013. Seksuele gezondheid in Vlaanderen. Gent: Academia Press.

Byrne, M., Doherty, S., McGee, H.M. and Murphy, A.W. 2010: General practitioner views about discussing sexual issues with patients with coronary heart disease: a national survey in Ireland. BMC Family Practice 11, 1-7.

Primary Health Care Research \& Development 2016; 17: 333-350
European Centre for Disease Prevention and Control. 2012: Projects. Retrieved 12 November 2012 from http:// ecdc.europa.eu/en/activities/diseaseprogrammes/hash/pages/ projects.aspx.

FPS Public Health, Food Chain Safety and Environment. 2007: An invitation to dialogue: law on patients' rights. Retrieved 18 December 2014 from http://www.health.belgium.be/ internet2Prd/groups/public/@public/@dg1/@legalmanagement/ documents/ie2divers/19081125.pdf.

Hinchliff, S., Gott, M. and Galena, E. 2004: GPs' perceptions of the gender-related barriers to discussing sexual health in consultations. European Journal of General Practice 10, 56-60.

Kang, M. 2007: Sex, contraception and health. Australian Family Physician 36, 594-600.

KCE. 2012: Position paper: organisation of care for chronic patients in Belgium. Retrieved 23 December 2012 from https://www.kce.fgov.be/publication/report/positionpaper-organisation-of-care-for-chronic-patients-in-belgium.

Khan, A., Plummer, D., Hussain, R. and Minichiello, V. 2007: Sexual risk assessment in general practice: evidence from a New South Wales survey. Sexual Health 4, 1-8.

Khan, A., Plummer, D., Hussain, R. and Minichiello, V. 2008: Does physician bias affect the quality of care they deliver? Evidence in the care of sexually transmitted infections. Sexually Transmitted Infections 84, 150-51.

Meystre-Agustoni, G., Jeannin, A., de Heller, K., Pécoud, A., Bodenmann, P. and Dubois-Arber, F. 2011: Talking about sexuality with the physician: are patients receiving what they wish? Swiss Medical Weekly 141, 1-6.

Mitchell, J.W., Harvey, S.M., Champeau, D., Moskowitz, D.A. and Seal, D.W. 2012: Relationship factors associated with gay male couples' concordance on aspects of their sexual agreements: establishment, type, and adherence. AIDS and Behavior 16, 1560-69.

Nusbaum, M.R.H. and Hamilton, C.D. 2002: The proactive sexual health history. American Family Physician 66, 1705-12.

Orzano, A.J., McInerney, C.R., McDaniel, R.R., Meese, A., Alajmi, B., Mohr, S.M., et al. 2009: A medical home: value and implications of knowledge management. Health Care Management Review 34, 224-33.

Padman, R., Shevchik, G., Paone, S., Dolezal, C. and Cervenak, J. 2010: EVisit: a pilot study of a new kind of healthcare delivery. Studies in Health Technology and Informatics 160, 262-66.

Parboosing, J. 2002: Physician communities of practice: where learning and practice are inseparable. Journal of continuing education in the health professions 22, 230-36.

Parish, S.J. and Clayton, A. 2007: Sexual medicine education: review and commentary. Journal of Sexual Medicine 4, 259-68.

Plsek, P.E. and Greenhalgh, T. 2001: The challenge of complexity in health care. British Medical Journal 323, 625-28.

Prestage, G., Mao, L., McGuigan, D., Crawford, J., Kippax, S., Kaldor, J. and Grulich, A.E. 2006: HIV risk and communication between regular partners in a cohort of HIV-negative gay men. AIDS Care 18, 166-72. 
Ralston, J.D., Carrell, D., Reid, R., Anderson, M., Moran, M. and Hereford, J. 2007: Patient web services integrated with a shared medical record: patient use and satisfaction. Journal of the American Medical Informatics Association 14, 798-806.

Richens, J., Copas, A., Sadiq, S.T., Kingori, P., McCarthy, O., Jones, V., et al. 2010: A randomised controlled trial of computer-assisted interviewing in sexual health clinics. Sexually Transmitted Infections 86, 310-14.

Sasse, A., Deblonde, J. and Van Beckhoven, D. 2013: Epidemiologie van AIDS en HIV-infectie in België: Toestand op 31 december 2012. Retrieved 23 February 2013 from https://www.wiv-isp.be/Documents/WIVISP_Rapport_HIV-AIDS_2012.pdf.

Sasse, A., Deblonde, J. and Van Beckhoven, D. 2014: Epidemiologie van AIDS en HIV-infectie in België: Toestand op 31 december 2013. Retrieved 2 January 2015 from https://www.wiv-isp.be/News/Documents/ Rapport_HIV-AIDS_2013_Print_Press.pdf.

Sasse, A., Verbrugge, R. and Van Beckhoven, D. 2012: Epidemiologie van AIDS en HIV-infectie in België: Toestand op 31 december 2011. Retrieved 23 December 2012 from https://www.wiv-isp.be/Documents/121219_ Rapport_HIV-AIDS_2011_5.pdf.

Sensoa. 2012: Acties. Retrieved 19 December 2012 from http://www.sensoa. be/acties.

Spark, S., Lewis, D., Vaisey, A., Smyth, E., Wood, A. and Temple-Smith, M. 2015: Using computer-assisted survey instruments instead of paper and pencil increased completeness of self-administered sexual behaviour questionnaires. Journal of Clinical Epidemiology 68, 94-101.

Tsimtsiou, Z., Hatzimouratidis, K., Nakopoulou, E., Kyrana, E., Salpigidis, G. and Hatzichristou, D. 2006: Predictors of physicians' involvement in addressing sexual health issues. Journal of Sexual Medicine 3, 583-88.

Verhoeven, V., Colliers, A., Verster, A., Avonts, D., Peremans, L. and Van Royen, P. 2007: Collecting data for sexually transmitted infections (STI) surveillance: what do patients prefer in Flanders? BMC Health Services Research 7, $1-4$.

Wimberly, Y., Hogben, M., Moore-Ruffin, J., Moore, S. and Fry-Johnson, Y. 2006: Sexual history-taking among primary care physicians. Journal of the National Medical Association 98, 1924-29.

Witry, M.J., Doucette, W.R., Daly, J.M., Levy, B.T. and Chrischilles, E.A. 2010: Family physician perceptions of personal health records. Perspectives in Health Information Management 1-8.

Wonca International Classification Committee. 2012: International classification of primary care: ICPC english. Retrieved 23 December 2012 from http://www.kith.no/upload/2705/ ICPC-2-English.pdf.

World Health Organisation (WHO). 2012: Health workforce: nursing and midwifery at WHO. Retrieved 23 December 2012 from http://www.who.int/hrh/nursing midwifery/en/.

\section{Appendix 1. Interview protocol for inquiring GPs in Flanders about their opinion of discussion and registration of HIV-risk factors}

Introduction of interviewer and explanation of the purpose of the interview. General explanation of the research aim and recording demographic data of $G P$ :

- Sex of interviewee

- Date of birth

- Date of interview

- Region of practice

\section{1 (Electronic) Medical Record (EMR)}

A. What does the EMR means for you?

Additional prompting:

- How do you use the EMR?

- How do you see the EMR (i.e. as a tool to plan care for patients, to support your memory, to communicate with other professionals in the practice and beyond, etc.)?

- Why do you use an Electronic Medical Record?

Is it rather a formality or does it have certain benefits; and if so, what are the benefits for you and for your patients?

- What is the main difference in practice for you between a paper record and an EMR?

- Who, except you, in the practice has access to the electronic medical record of patients?

- What are limitations in access according to discipline?

- Is the EMR a support for communicating in the professional team?

- Does the electronic medical record for you have a different or additional meaning or purpose in the context of patients at risk for HIV compared to other patients?

B. In your opinion, what is the additional value of an EMR for the care for patients, compared with a paper record?

Additional prompting:

- What is the different value regarding continuity of high quality care or person centred care?

- What are disadvantages of the electronic medical record for you as a GP? (e.g., privacy of sensitive sexual health information) 
C. What personal data of your patients do you register in the medical record?

Additional prompting:

- What do you do with data regarding the sexual orientation of your patient?

- Do you standardly register other aspects in the EMR with regard to men who have sex with men and why? (e.g. history of STI's, partner relationship, sexual orientation).

- If the GP does register different information for this patient group: Are there other patient groups you register different information for and why? Who has access to these data in the record and why?

- If the GP does not register different information for this patient group: Are there other patient groups for which you do register different information and why? What is the reason for not registering for instance the sexual orientation? Would you register whether a patient smokes?

- What information you register for smokers that you don't register for non-smokers?

- What is the difference for you to register whether someone smokes and whether someone has sexually risky behaviour?

D. In your opinion, is it relevant to register certain personal data as asked priori for all patients?

Additional prompting:

- If so: When would you do this? Why would you do this? How (would you) do you register this?

- If not: Why not?

\section{Risk factors}

A. When do you conduct a sexual history for your patients in your practice?

Additional prompting:

- In case the GP does not conduct a sexual history: If a 17 year old girl encounters you to ask for a prescription for birth control,

What do you inquire and/or what do you discuss?

From this discussion, what do you register in the record of the patient?

If you don't register anything of this discussion, what is the reason for not doing that?

- When a man encounters you to ask for a prescription for Viagra ${ }^{\circledR}$,

What do you inquire?

Primary Health Care Research \& Development 2016; 17: 333-350
Do you register any of this information in the record?

What do you register in the record of the patient?

If you don't register anything of this discussion, what is the reason for not doing that?

- In case the GP does conduct a sexual history: what are questions asked during this discussion? What is the frequency or when do you conduct a sexual history?

What are differences according to patient groups?

What do you register in the medical record regarding this discussion?

What is your feeling whilst conducting a sexual history of a patient?

Does this feeling vary according to the sex, the age, sexual orientation, etc. of the patient?

B. When, in your opinion, is a sexual history relevant for a patient?

Additional prompting:

- If the GP does conduct sexual histories from patients: what do you register in the record?

- If the GP does not conduct sexual histories from patients: imagine a patient who encounters you with symptoms of gonnorea, what do you ask this patient and what do you register of this encounter in the medical record? Does this, in your opinion, is a relevant situation to conduct a sexual history and why?

C. If you were asked to inquire patients to estimate their risk for STI's in general and HIV in particular, what would you ask these patients?

Additional prompting:

- What is the difference for you to inquire about behaviour (e.g., unsafe sexual contact or frequent visits to a gay sauna) and more objective elements (e.g., antecedents of STI's)?

- What makes the difference between these two things in inquiring the patient?

- What would you register in the medical record? Does this make a difference in registering in the record and why?

- Analogy smoking patient (risk behaviour) versus sexually risky behaviour.

- If a patient present him-/herself with an STI after having unsafe sexual contact outside of the partner relationship, would you consider 
this as a risk factor for HIV? What do you register in the medical record? If his/her partner is a patient in your practice as well, what would you do?

\section{Registration}

A. If a patient at risk (for STI's, HIV) sits in front of you and you register elements in the medical record, which elements are these?

Additional prompting:

- Are these elements you also register for patients who are not at risk?

- What do you need for more systematic registration of these topics?

- If the GP registers: once you registered a patient as being a patient at risk for STI's, what happens next? What can you do within the consult? What would you like to do? What do you think must be done once the patient has this 'label'?

- If the patient is referred to another GP, what happens with the information about him/her being a patient at risk? What happens with the information in case of a referral to secondary care?

- What does a patient have to do to 'lose' this 'label'?

B. Do you use a certain structure, words or codes or free text for registering?

Additional prompting:

- Who knows the meaning of these codes/free text fragments/...?

- If a man encounters you and you find out he cheated on his wife by having sexual contact with a man ... What do you register in the record and how? Where - if the GP does - do you register this information? Why don't you register this information.

\section{Patients' contribution}

What is your opinion about asking patients for permission to register more 'sensitive' personal information in the record?

Additional prompting:

- How, in your opinion, could patients be more involved in the registration of risk factors for STI's, HIV in particular?

\section{Short survey}

I will state some ways in which literature suggest risk factors for patients at risk could be registered. Could you give me your opinion about each of these and reflect on it?

- Standard registration (coding) by you as GP?

e.g. ICD10 Chlamydia infection of rectum and anus.

e.g. Tick boxes for patients

- Short summary of the risk by you as GP?

e.g. Space for free text where you can register what in your opinion the risk is the patient has?

- Standard questions in the record that you, might or might not, go over with and fill out with the patient?

- History-taking document/survey that you give to the patient and he/she delivers it back during the next consultation?

- Online registration by the patient (possibly linked to the electronic medical record that you hold)?

- Any other suggestions? 
Appendix 2 Flexible model for analysis

\begin{tabular}{|c|c|c|}
\hline Level of analysis & Analytic category & Operational category \\
\hline \multicolumn{3}{|l|}{$\begin{array}{l}\text { 1. The electronic medical } \\
\text { record (EMR) }\end{array}$} \\
\hline \multirow[t]{15}{*}{ Meaning EMR for GP } & Use of EMR & Working tool \\
\hline & & Communication tool \\
\hline & & Support tool \\
\hline & & Memory tool \\
\hline & & Streamlined data collection and classification \\
\hline & Additional value and benefits of & Keeping an overview \\
\hline & EMR (compared with paper file) & Structure content \\
\hline & & Decrease of practical/administrative burden \\
\hline & & More complete and direct \\
\hline & & Continuity of care and patient informations \\
\hline & & Back-up of data \\
\hline & Disadvantages and risks of EIVIR & Programme layout of EMR's \\
\hline & & lechnical issues \\
\hline & & \\
\hline & & Conformity and punctuality \\
\hline \multirow{7}{*}{$\begin{array}{l}\text { EMR for patient } \\
\text { according to GP }\end{array}$} & Benefits for patients & Quality of care \\
\hline & & Continuity of care \\
\hline & & Patients with chronic or long-term conditions \\
\hline & & Safety/reassurance \\
\hline & & Awareness of risk \\
\hline & Disadvantages for patients & Computer as second patient \\
\hline & & Missing data from other institutions of health \\
\hline \multirow[t]{8}{*}{ Access to EMR } & Accessibility by professionals & No policy \\
\hline & outside practice & External professionals never \\
\hline & Accessibility in solo practice & Only the GP \\
\hline & Accessibility in small group & No written policy \\
\hline & practices & Only the GPs \\
\hline & & Additional administrative staff \\
\hline & Access regulation in local health & No policy \\
\hline & centres (interdisciplinary teams) & Depending on discipline \\
\hline \multirow{16}{*}{$\begin{array}{l}\text { 2. Personal data in the } \\
\text { EMR }\end{array}$} & Administrative patient data & Country of origin (for Africans), ethnicity \\
\hline & & Job and/or education level \\
\hline & & Contact information and/or address \\
\hline & & Date of birth \\
\hline & & Marital status \\
\hline & Elements regarding medical & Family/genetics \\
\hline & history/antecedents & Medical history \\
\hline & & Orthopaedic antecedents \\
\hline & & Complaints \\
\hline & & Medication list \\
\hline & & Allergies \\
\hline & & Substance abuse smoking/alcohol (and frequency) \\
\hline & Social and/or psychiatric & Vague conceptualisation of topics \\
\hline & informations & No obvious place in EMR \\
\hline & Registration sensitive sexual & Non-systematic registration \\
\hline & health informations & $\begin{array}{l}\text { Medical record often too medical orientated } \\
\text { Relying on memory of GP }\end{array}$ \\
\hline
\end{tabular}


Appendix 2 Continued

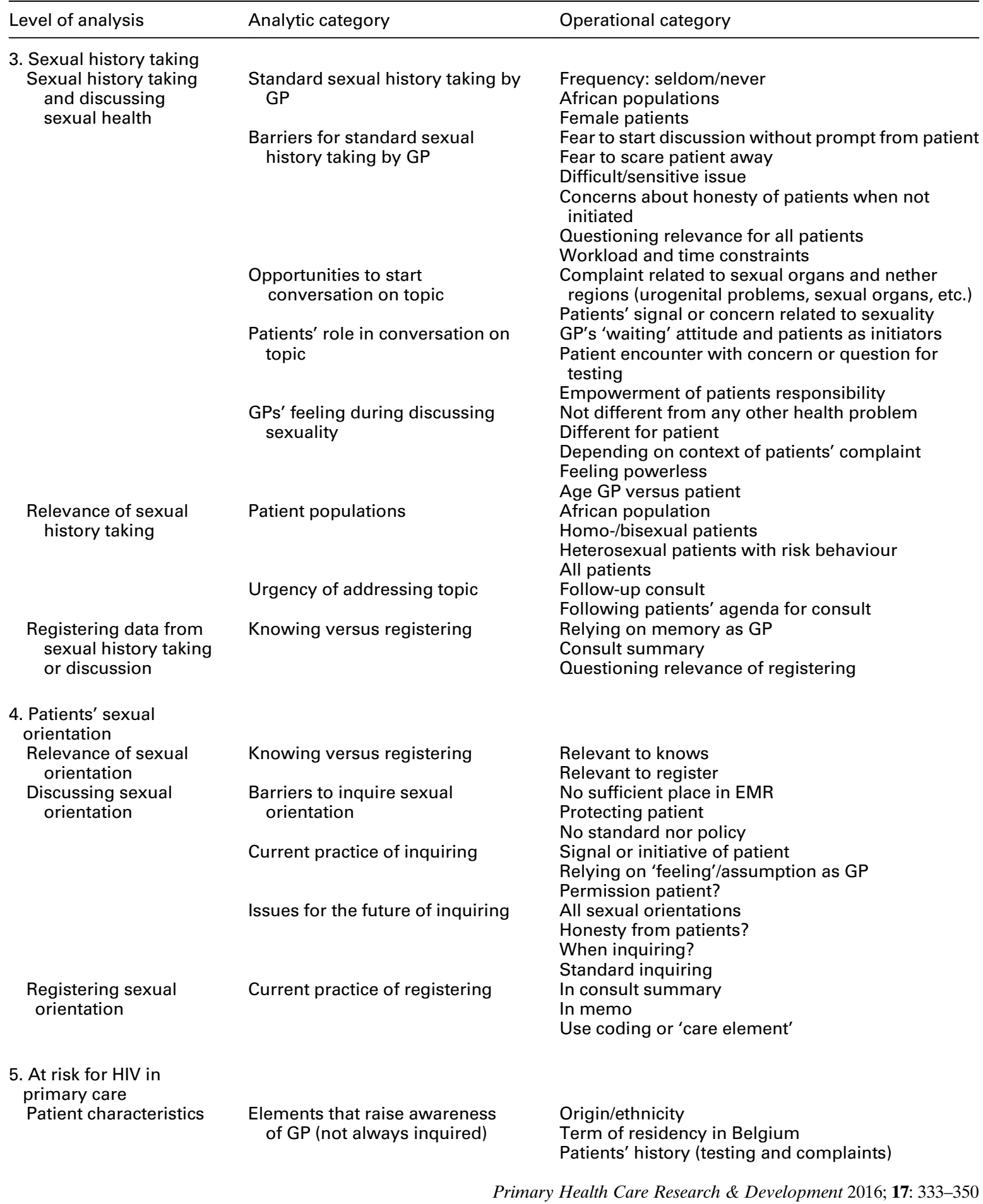




\section{Jolien Vos et al.}

Appendix 2 Continued

\begin{tabular}{|c|c|c|}
\hline Level of analysis & Analytic category & Operational category \\
\hline Indicators used by GPs & $\begin{array}{l}\text { Vulnerable populations } \\
\text { Increasing awareness of GP } \\
\text { (inquired or present in EMR) }\end{array}$ & $\begin{array}{l}\text { Sexual orientation: homo-/bisexuals } \\
\text { Heterosexuals with risk } \\
\text { (IV) drug users } \\
\text { Family members with HIV } \\
\text { Sexually risky behaviour } \\
\text { Job in sex industry } \\
\text { Unwanted/unplanned pregnancy } \\
\text { Youth } \\
\text { Older men } \\
\text { Lower educated } \\
\text { History of STI's } \\
\text { History of (uro)genital complaints } \\
\text { History of complaints related to sexual organs, } \\
\text { nether regions } \\
\text { Current complaints }\end{array}$ \\
\hline
\end{tabular}

6. Proactive approach for sexually risky behaviour Discussion of risk

Registration of risk
Needed for discussion

Appropriate moment for
discussion

How discussing the topic

Current practice registering

Expressed needs for proactive registering sexual orientation

Expressed needs for proactive registering sexual risk
Band of trust with patient

Training and education

General flyers and posters

Research regarding patients' experience

Time and realistic?

Standard during intake

Sufficient place in EMR

Media attention

Responsibility from the patient

Currently lack of standard

Intake survey

Along consultation continuum

Sexual orientation $=$ intake

Sexual history $=$ later on

Patients' initiative

Survey together with patent

Survey autonomic by patient

Online survey by patient

Survey as GPs' support

First contact versus later

Need for trust

Doubted need for all patients

Information unknown

Information in GPs' memory

Information reported in team meeting

Information in consult

Summary

Lack of clarity for colleagues

No ICPC code

Tool for more/better discussion

Tool for more/better registering

Increasing visibility and clarity

Increase systematic/standard practice

Decision for in-depth sexual history by GP

Sufficient place in EMR

Policy or guidelines

Enabling free text

Enabling adjustments

Sufficient place in EMR 
Appendix 2 Continued

\begin{tabular}{|c|c|c|}
\hline Level of analysis & Analytic category & Operational category \\
\hline & $\begin{array}{l}\text { Case studies gonorrhoea, } \\
\text { contraception, etc. }\end{array}$ & $\begin{array}{l}\text { Increasing visibility and clarity } \\
\text { Policy or guidelines } \\
\text { Inquiring sexual partners and testing } \\
\text { Cheating } \\
\text { Reporting } \\
\text { Complaint/diagnosis } \\
\text { Partner record } \\
\text { Why behind question } \\
\text { Nature of prescription } \\
\text { Discussing sexuality } \\
\text { Implications for partners } \\
\text { Sexual education }\end{array}$ \\
\hline \multirow[t]{4}{*}{$\begin{array}{l}\text { 7. Patients 'labelled' at } \\
\text { risk in EMR }\end{array}$} & $\begin{array}{l}\text { GPs approach within the consult } \\
\text { of a 'patient at risk' }\end{array}$ & $\begin{array}{l}\text { Counselling, informing, motivating } \\
\text { Approach depending on test result } \\
\text { Feeling powerless } \\
\text { Empowering of patients' responsibility } \\
\text { Education regarding correct use of contraceptives }\end{array}$ \\
\hline & $\begin{array}{l}\text { Referring a 'patient at risk' to a } \\
\text { general specialist }\end{array}$ & $\begin{array}{l}\text { Information in letter depends on reason for referral } \\
\text { HIV information versus risk behaviour } \\
\text { Discussing referral letter with patient } \\
\text { Motivating when resistance } \\
\text { Responsibility of specialist } \\
\text { GP makes first selection of information }\end{array}$ \\
\hline & Change of GP by 'patient at risk' & $\begin{array}{l}\text { Sexually risky behaviour versus history of testing } \\
\text { Print-out, back-up } \\
\text { Consent of patient } \\
\text { In case of HIV - referral to specialised clinic } \\
\text { Patient confidentiality is priority, motivating patient } \\
\text { to tell }\end{array}$ \\
\hline & $\begin{array}{l}\text { Evolution of the label 'patient at } \\
\text { risk' }\end{array}$ & $\begin{array}{l}\text { Deleting from EMR not necessary } \\
\text { Inactivating } \\
\text { Adjusting during follow-up } \\
\text { Chronicity } \\
\text { Normality }\end{array}$ \\
\hline \multirow[t]{3}{*}{$\begin{array}{l}\text { 8. Differences and } \\
\text { similarities between } \\
\text { sexually risky behaviour } \\
\text { and other risk } \\
\text { behaviours }\end{array}$} & $\begin{array}{l}\text { Smoking versus sexually risky } \\
\text { behaviour }\end{array}$ & $\begin{array}{l}\text { Unambiguous yes/no question } \\
\text { Prevalence of behaviour differs } \\
\text { Publicity of behaviour differs } \\
\text { Different in emotional load } \\
\text { Different in sufficient place EMR } \\
\text { Both responsibilities for patient } \\
\text { Both risk behaviour } \\
\text { Both potentially disappointing results }\end{array}$ \\
\hline & $\begin{array}{l}\text { Behaviours with similar } \\
\text { atmosphere }\end{array}$ & $\begin{array}{l}\text { Physical abuse } \\
\text { Substance abuse } \\
\text { Sexual dysfunctions } \\
\text { Psychiatric problems } \\
\text { Arranged marriage } \\
\text { Correct use of contraception }\end{array}$ \\
\hline & Experienced problems & $\begin{array}{l}\text { Ease to discuss } \\
\text { Lying or minimalising } \\
\text { Spontaneity is limited } \\
\text { Registration in EMR is difficult }\end{array}$ \\
\hline
\end{tabular}




\section{Jolien Vos et al.}

Appendix 2 Continued

\begin{tabular}{lll}
\hline Level of analysis & Analytic category & Operational category \\
\hline 9. GPs' role and tasks & Sexual orientation & $\begin{array}{l}\text { Relevance of knowing } \\
\text { Integrated in intake consult } \\
\text { Ability to adjust } \\
\end{array}$ \\
& Epidemiological importance \\
& Dexual history taking & Relationship of trust \\
& Relevance for all patients \\
& Best position to do this \\
& Knowledge of patients' context \\
& Shared responsibility \\
& Waiting attitude
\end{tabular}

$\mathrm{STI}=$ sexually transmitted infection; ICPC $=$ International Classification of Primary Care 